\title{
Evaluation of Right Ventricular Functions in Patients of Left Ventricular Hypertrophy
}

\author{
Abhishek Bhatia; Nishant Wadhera; Shirobhisharma;Abhishek Gupta; \\ S.K.Virmani.
}

\begin{abstract}
Aims And Objectives: To evaluate the Right Ventricular functions in patients of Left Ventricular Hypertrophy.Common conditions that effect the left ventricle causing dysfunction areIschemic heart disease, Cigarette smoking, Hypertension (high blood pressure), Obesity; Diabetes; Valvular heart disease ; Cardiomyopathies.

Left Ventricular Hypertrophy (LVH) or increased left ventricular mass (LVM) is a risk factor for cardiovascular disease. . Patterns like concentric hypertrophy (increase in both ventricular mass and relative wall thickness), eccentric hypertrophy (increase in left ventricular mass with normal relative wall thickness, concentric remodeling (increase in relative wall thickness) are identified that carry different risk for cardiovascular events ${ }^{2}$. 2 -Dimensional Echocardiography (2D ECHO) is also considered as a gold standard tool for diagnosing left ventricular hypertrophy ${ }^{4}$.

Methods: cross sectional of 115 patients with risk factor of developing LVH.
\end{abstract}

Inclusion criteria:

\section{Introduction}

All the Patients diagnosed with Left Ventricular hypertrophy on ECG and ECHO. Target population will be with risk factors of Left Ventricular Hypertrophy (Hypertension, aortic stenosis, aortic regurgitation, mitral regurgitation)

Exclusion criteria:

All the primary causes of Right Ventricular hypertrophy or dysfunction will be excluded from the study. (Example)

- Chronic obstructive pulmonary disease

- Right Ventricular infarct

- Mitral Stenosis

- Primary pulmonary hypertension

- Bronchial Asthma

- Ischemic Heart Diseases

- Pulmonary Embolism

All the patients who did not give consent for the study.

Diagnostic criteria for $\mathrm{LVH}^{3}$

\begin{tabular}{|l|l|}
\hline Parameter & Criteria \\
\hline Sokolow-Lyon index & $\mathrm{SV}_{1}+\left(\mathrm{RV}_{5}\right.$ or $\left.\mathrm{RV}_{6}\right)>3.5 \mathrm{mV}$ \\
\cline { 2 - 3 } & $\mathrm{RaVL}>1.1 \mathrm{mV}$ \\
\hline Rornhilt-Estes point score system (points) [*] & Any limb lead $\mathrm{R}$ wave or $\mathrm{S}$ wave $>2.0 \mathrm{mV}$ (3) \\
\cline { 2 - 3 } & or $\mathrm{SV}_{1}$ or $\mathrm{SV}_{2} 3.0 \mathrm{mV}(3)$ \\
\cline { 2 - 3 } & or $\mathrm{RV}$ to $\mathrm{RV}_{6} 3.0 \mathrm{mV}(3)$ \\
\cline { 2 - 3 } & $\begin{array}{l}\mathrm{ST}-\mathrm{T} \text { wave abnormality (no digitalis therapy) } \\
(3)\end{array}$ \\
\cline { 2 - 3 } & ST-T wave abnormality (digitalis therapy) (1) \\
\cline { 2 - 3 } & Left atrial abnormality (3) \\
\cline { 2 - 3 } & Left axis deviation <-30 degrees (2) \\
\cline { 2 - 2 } & QRS duration >90 msec (1) \\
\cline { 2 - 2 } & $\begin{array}{l}\text { Intrinsicoid deflection in } \mathrm{V}_{5} \text { or } \mathrm{V}_{6}>50 \mathrm{msec} \\
(1)\end{array}$ \\
\hline
\end{tabular}


Evaluation of Right Ventricular Functions in Patients of Left .... a

\begin{tabular}{|l|l|}
\hline \multirow{2}{*}{ Cornell voltage criteria } & $\mathrm{SV}_{3}+\mathrm{SaVL}>2.8 \mathrm{mV}$ (for men) \\
\cline { 2 - 2 } & $\mathrm{SV}_{3}+\mathrm{SaVL}>2.0 \mathrm{mV}$ (for women) \\
\hline \multirow{3}{*}{ Cornell voltage duration } & QRS duration $x$ Cornell voltage $>2436$ \\
\cline { 2 - 2 } & QRS duration $\mathrm{x}$ sum of voltages in all leads $>$ \\
& 17,472 \\
\hline
\end{tabular}

The American Society of Echocardiography criteria for $\mathrm{LVH}^{5}$

\begin{tabular}{|c|c|c|c|c|c|c|c|c|}
\hline \multirow[b]{3}{*}{ Measure } & \multicolumn{4}{|c|}{ Women } & \multicolumn{4}{|c|}{ Men } \\
\hline & \multirow[b]{2}{*}{$\begin{array}{l}\text { Referencee } \\
\text { Range }\end{array}$} & \multirow[b]{2}{*}{ Mildly } & \multicolumn{2}{|l|}{ Abnormal } & \multirow[b]{2}{*}{$\begin{array}{l}\text { Reference } \\
\text { Range }\end{array}$} & \multicolumn{3}{|c|}{ Abnormal } \\
\hline & & & Moderately & Severely & & Mildly & Moderately & Severely \\
\hline \multicolumn{9}{|c|}{ Linear Method } \\
\hline \begin{tabular}{|l} 
Septal \\
thickness \\
$(\mathrm{cm})$
\end{tabular} & $0.6-0.9$ & $\begin{array}{l}1.0- \\
1.2\end{array}$ & $1.3-1.5$ & $>1.6$ & $0.6-1.0$ & $\begin{array}{l}1.1- \\
1.3\end{array}$ & $1.4-1.6$ & $>1.7$ \\
\hline $\begin{array}{l}\text { Posterior } \\
\text { wall } \\
\text { thickness } \\
(\mathrm{cm}) \\
\end{array}$ & $0.6-0.9$ & $\begin{array}{l}1.0- \\
1-2\end{array}$ & $1.3-1.5$ & $>1.6$ & $0.6-1.0$ & $\begin{array}{l}1.1- \\
1.3\end{array}$ & $1.4-1.6$ & $>1.7$ \\
\hline \multicolumn{9}{|c|}{ 2D method } \\
\hline $\begin{array}{l}\text { LV mass } \\
(\mathrm{gm})\end{array}$ & $66-150$ & $\begin{array}{l}151- \\
171\end{array}$ & $172-182$ & $>183$ & $96-200$ & $\begin{array}{l}201- \\
227\end{array}$ & $228-254$ & $>255$ \\
\hline
\end{tabular}

Reference Limits and Partition Values of Right Ventricular (RV) Size and Function as Measured in the Apical Four Chamber View ${ }^{5}$

\begin{tabular}{|l|l|l|l|l|}
\hline \multirow{2}{*}{ Dimension } & \multirow{2}{*}{$\begin{array}{l}\text { Reference } \\
\text { Range }\end{array}$} & Abnormal & Meverely \\
\cline { 3 - 5 } & & Mildly & Moderately & $>38$ \\
\hline RV diastolic area $\left(\mathrm{cm}^{2)}\right.$ & $11-28$ & $29-32$ & $33-37$ & $>23$ \\
\hline RV systolic area $\left(\mathrm{cm}^{2)}\right.$ & $7.5-16$ & $17-19$ & $20-22$ & $<17$ \\
\hline $\begin{array}{l}\text { RV fractional area change } \\
\% \text { area change (\%) }\end{array}$ & $32-60$ & $25-31$ & $18-24$ & \\
\hline
\end{tabular}

Reference Limits and Partition Values of Right Ventricular $(\mathrm{RV})^{5}$

\begin{tabular}{|l|l|l|l|l|}
\hline Dimension & Reference Range & Abnormal & \multicolumn{2}{l|}{} \\
\cline { 3 - 5 } & & Mildly & Moderately & Severely \\
\hline RV dimension & $2.9-3.3$ & $3.4-3.8$ & $>3.9$ \\
\hline $\begin{array}{l}\text { Basal RV diameter } \\
\text { (cm) }\end{array}$ & $2.0-2.8$ & $3.4-3.7$ & $3.8-4.1$ & $>4.2$ \\
\hline $\begin{array}{l}\text { Mid RV diameter } \\
\text { (cm) }\end{array}$ & $2.7-3.3$ & $8.0-8.5$ & $8.6-9.1$ & $>9.2$ \\
\hline $\begin{array}{l}\text { Base-to-apex length } \\
\text { (cm) }\end{array}$ & $7.1-7.9$ & & & \\
\hline
\end{tabular}

\section{Observation:-}

Age and Sex wise distribution of subject

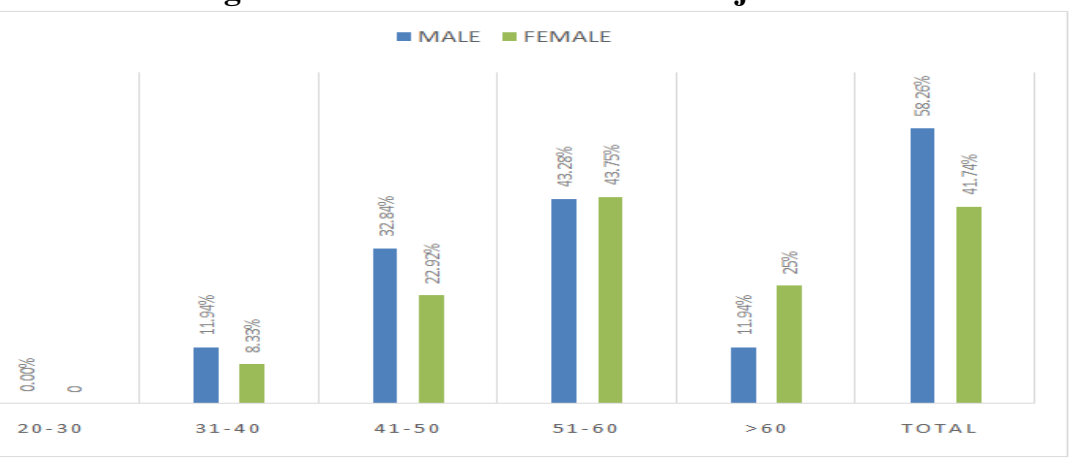


Pre-existing medical conditions in subjects

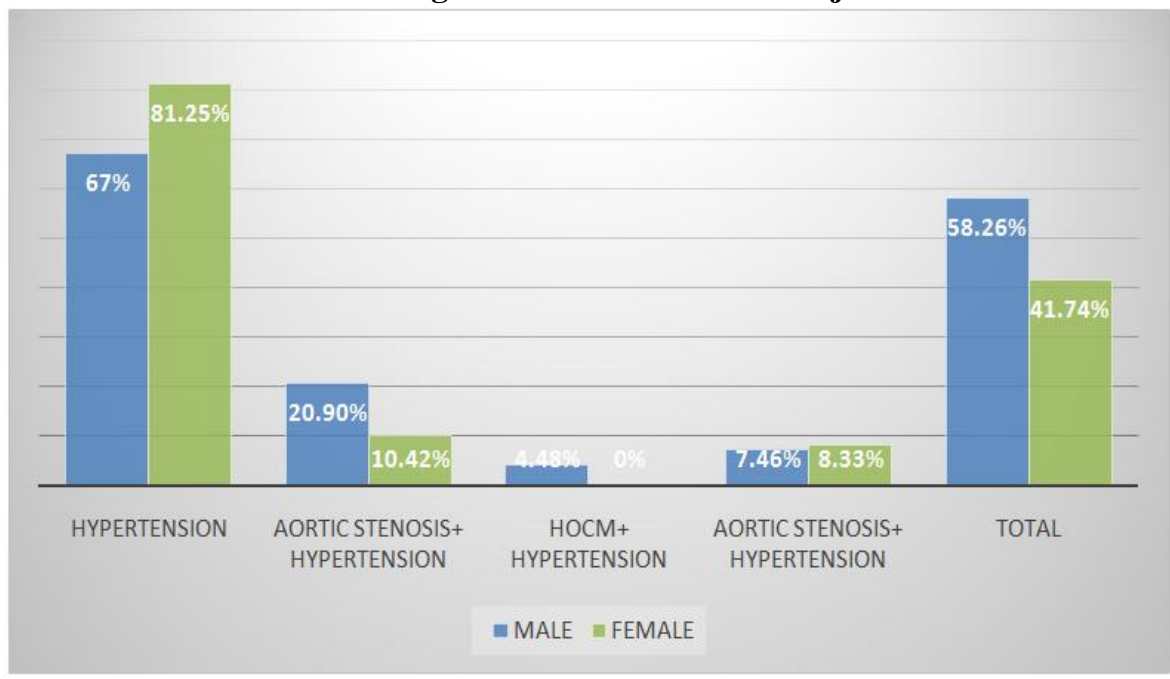

Number of subjects found to have LVH on ECG by using all the four criteria

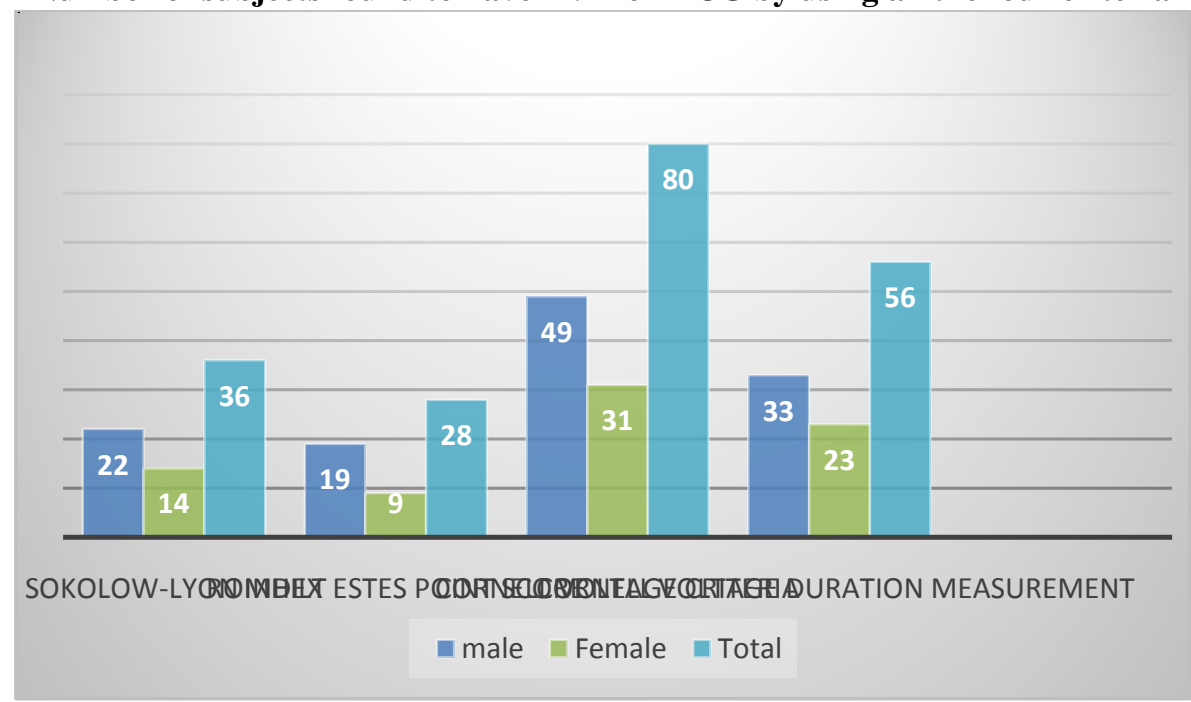

Number of patients confirmed to have LVH by ECHO amongst the patients found positive to have LVH by ECG

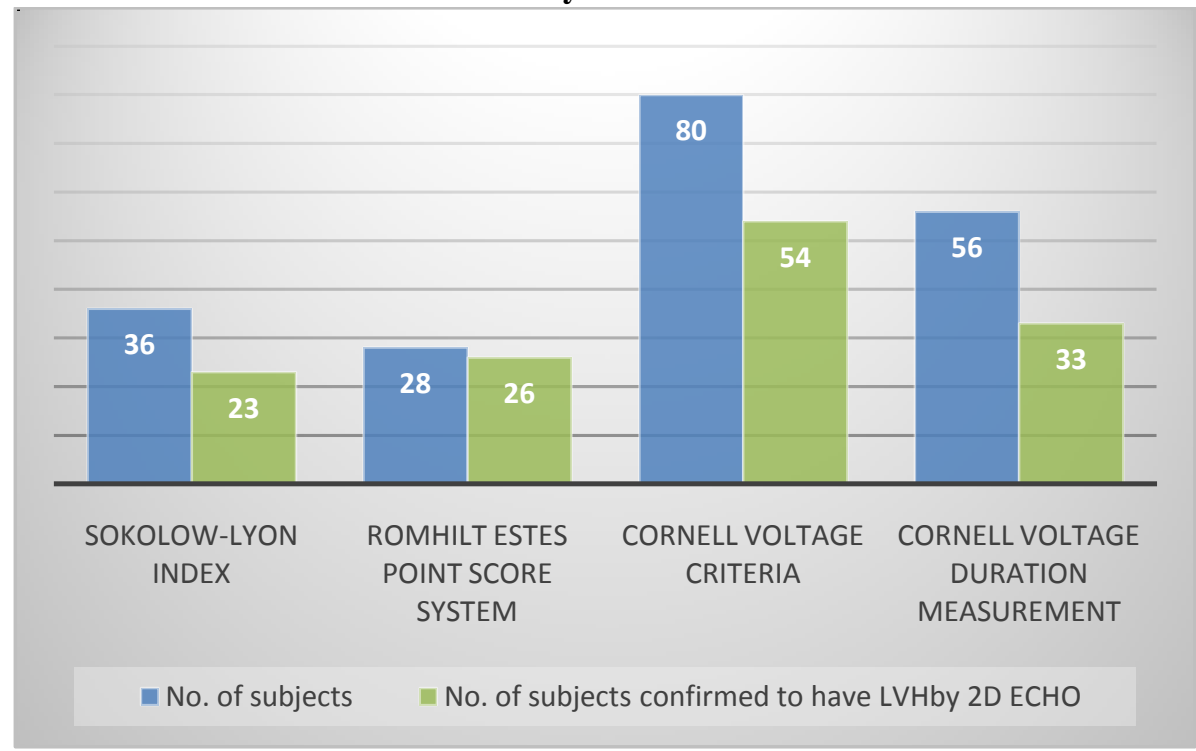




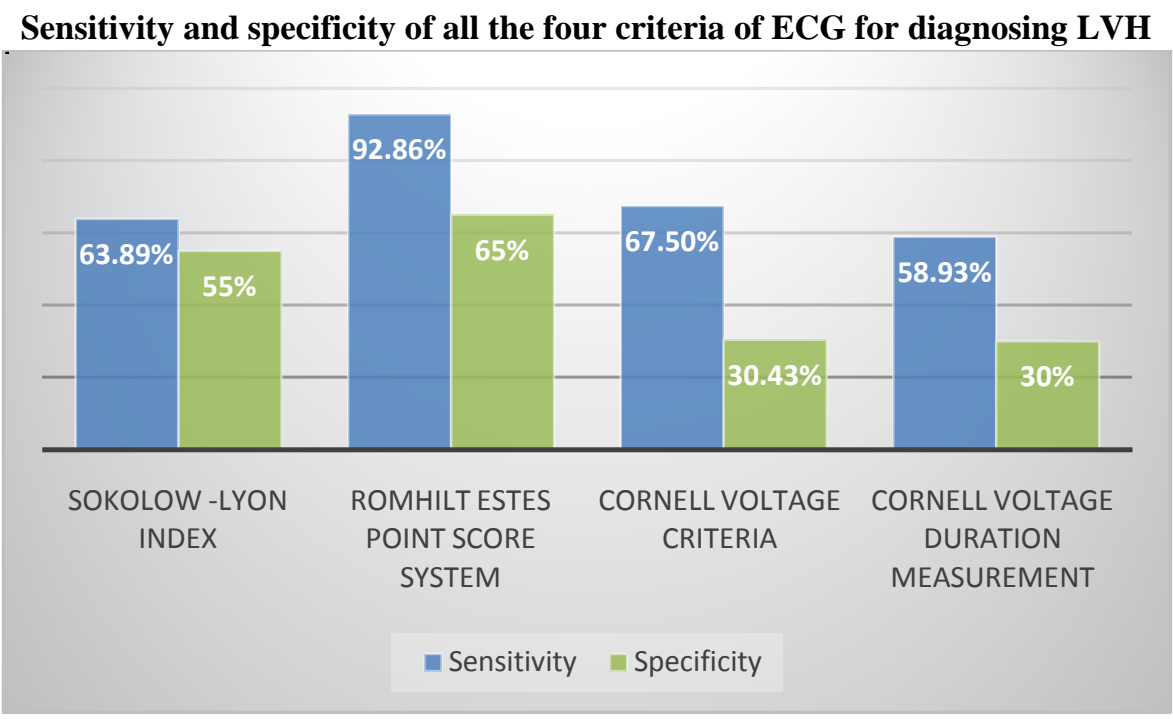

Study analysis

\begin{tabular}{|l|l|l|l|}
\hline \multicolumn{5}{|l|}{ Total number of subjects in the study group, N=115 } & Control Group & z-value \\
\hline & Study Group & 58 & - \\
\hline Number of patients & 57 & 0 & NA \\
\hline Positive for LVH by ECHO & $\begin{array}{l}(0.00 \%) \\
(100.00 \%)\end{array}$ & 0 & \\
\hline RV Dysfunction & 9 & 0 & \\
\hline Systolic only & 28 & 2 & \\
\hline Diastolic only & 10 & & \\
\hline Both &
\end{tabular}

The table above depicts a summary of the study in which in the study group out of 57 patients screened for RV dysfunction, 9 had systolic dysfunction, 28 had diastolic dysfunction and 10 had both systolic and diastolic dysfunction. Hence, total patients with systolic dysfunction were 19(33\%), with diastolic dysfunction were $38(67 \%)$ and total patients with RV dysfunction were 47(82\%).

\section{Summary And Conclusion}

The study was carried out to evaluate of right ventricular function in subjects of left ventricular hypertrophy using 2D echocardiography. The study included a total of 115 subjects with risk factors of developing LVH. Out of 115 subjects 67(58.26\%) were males and 48(41.74\%) were females, Out of the total 67 males, $51(76.12 \%)$ were between the age group of 41-60 years. Amongst the females $33(68.75 \%)$ were above the age of 51 years. Hypertension was the risk factor found in most $(92.17 \%)$ of the subjects followed by aortic stenosis and HOCM (3\%). All the subjects were then screened by ECG for LVH, following which all the subjects underwent 2D echocardiographic examination for confirmation of LVH and evaluation of RV function.

Out of the 57 subjects screened for RV function in study group, 47(82\%) subjects had RV dysfunction, out of which 19(40\%) subjects had systolic dysfunction and 38(60\%) had diastolic dysfunction. Out of the 47 subjects with RV dysfunction in the study group 10(21\%) had both systolic and diastolic dysfunction.

Comparing to subjects in control group which had only $2(3 \%)$ subjects with both systolic and diastolic dysfunction and no subjects with systolic and diastolic dysfunction alone. This difference in the study and control group was found to be statistically significant $(\mathrm{p}=0.0001, \mathrm{~S})$.

On analyzing the ECG as a whole by using all the four criteria we found that 80 subjects had LVH by ECG, out of which only 54(68\%) were confirmed by 2D ECHO. On analyzing the individual criteria we found that Romhilt Este's point Score System was the only statistically significant $(\mathrm{p}=0.0001)$ system for diagnosing $\mathrm{LVH}$, having sensitivity of $92.86 \%$ and specificity of $65 \%$ and a positive predictive value of $93 \%$. Rest all the three systems, Sokolow-Lyon index ( $\mathrm{p}=0.05$, NS), Cornell Voltage Criteria $(\mathrm{p}=0.75, \mathrm{NS})$ and Cornell voltage duration measurement $(\mathrm{p}=0.15, \mathrm{NS})$ were all statistically insignificant systems for diagnosing LVH.

\section{Hence from our study we could infer that:-}


1) The subjects with LVH have a significantly higher incidence of developing echocardiographic features of right ventricular dysfunction which are early indicators of right heart failure as compared to subjects with no LVH, with risk factors for developing LVH being common to all subjects.

2) RV dysfunction in subjects with LVH was independent of age and sex, as observed in the subjects of our study group.

3) Romhilt Este's point Score System was the only significant system for diagnosing LVH by ECG, with a high positive predictive value (93\%) rest of the three systems are statistically insignificant.

4). For diagnosing LVH, positive predictive value of ECG using all four systems was $58.39 \%$ whereas negative predictive value was $47.92 \%$, which means only $58 \%$ of all the subjects diagnosed to have LVH on ECG will be positive by ECHO.

\section{Limitations Of The Present Study}

1). Conventional methods or echocardiography were used in our study, Interpretations would be more accurate with the use of advanced methods available, like Tissue Doppler, Transesophageal echocardiography and MR angiography.

2) Some of the parameters used in our study like E/ A ratio, Mid RV diameter, were earlier considered good parameters for evaluation of RV function. The new and advanced techniques available for screening are considered better to the above stated parameters of conventional 2D Echocardiography.

\section{References}

[1]. Kannel WB, Gordon T, Castelli WP, Margolis JR. Electrocardiographic left ventricular hypertrophy and risk of coronary heart disease: the Framingham study. Ann Intern Med. 1970; 72: 813-822.

[2]. Ganau A, Devereux RB , Roman MJ , Simone G, Pickering TG, Saba PS , Vargiu P, Simongini I, Larah JH, Patterns of Left Ventricular Hypertrophy and geometric remodeling in essential hypertension. J Am CollCardiol. 1992; 19: 1550-1558.

[3]. Antikainen R, Grodzicki T, Palmer AJ, Beevers DG, Coles EC, Webster J, et al. The determinants of left ventricular hypertrophy defined by Sokolow-Lyon criteria in untreated hypertensive patients. J Hum Hypertens 2003; 17: 159-164.

[4]. Levy D, Girrison R J, Savage DD, Kannel W B , Castelli W P. Prognostic Implication of Echocardiographically determined Left Ventricular Mass in the Framingham Heart Study. N Engl J Medicine.1990; 322: 1561-1566.

[5]. Braunwalds, Heart Diseases, A Textbook Of Cardiovascular Medicine, 8th Edition, Chapter 14, page 243 - 251

[6]. Carlsson MB, Tragardh E, Engblom H, et al. Left ventricular mass by 12-lead electrocardiogram in healthy subjects: Comparison to cardiac magnetic resonance imaging . J. Electrocardiol 2006; 39:67.

[7]. Tabata T, Oki T, Yamada H, Abe M, Onose Y, Thomas JD. Subendocardial motion in hypertrophic cardiomyopathy: assessment from long- and short-axis views by pulsed tissue Doppler imaging. J Am SocEchocardiogr. 2000; 13: 108-115.

[8]. Pedrinelli,, Roberto Canale, Maria Laura, Giannini, Cristina, Talini, Enrica, Penno, Giuseppe Di Bello, Giulia, Di Bello, Vitantonio. Right ventricular dysfunction in early systemic hypertension/Journal of Hypertension. March 2010 ; 28: 615-621

[9]. Levy D, Anderson KM, Savage DD, Kannel WB, Christiansen JC, Castelli WP. Echocardiographically detected left ventricular hypertrophy: prevalence and risk factor.The Framingham Heart Study. Ann Intern Med 1988; 108: 7-13.

[10]. Savage DD, Garrison RJ, Kannel WB, Levy D, Anderson SJ, Stokes J III, et al. The spectrum of left ventricular hypertrophy in a general population sample: the Framingham Study. Circulation 1987; 75:126-133. 